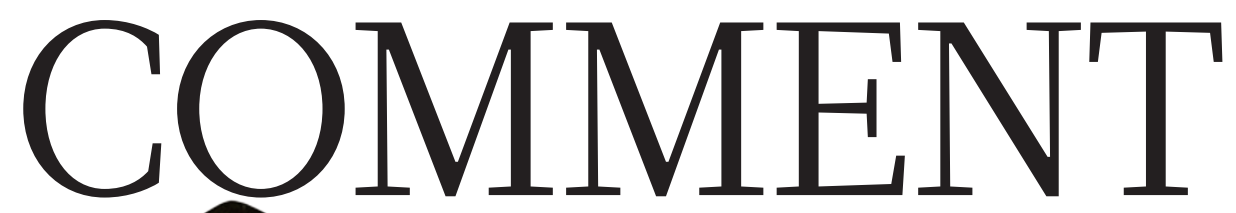

BRAIN Memory-dampening drugs have more benefits than risks $\mathbf{p . 2 7 5}$

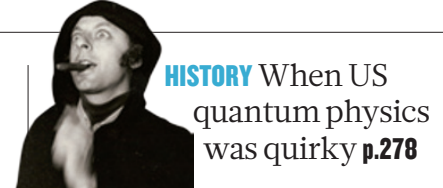

TAXONOMY Strip unwise Homo of sapiens rider until we mend our destructive ways $\mathbf{p . 2 8 2}$
OBITUARY John Marburger, science adviser to President Bush, remembered $\mathbf{p . 2 8 4}$

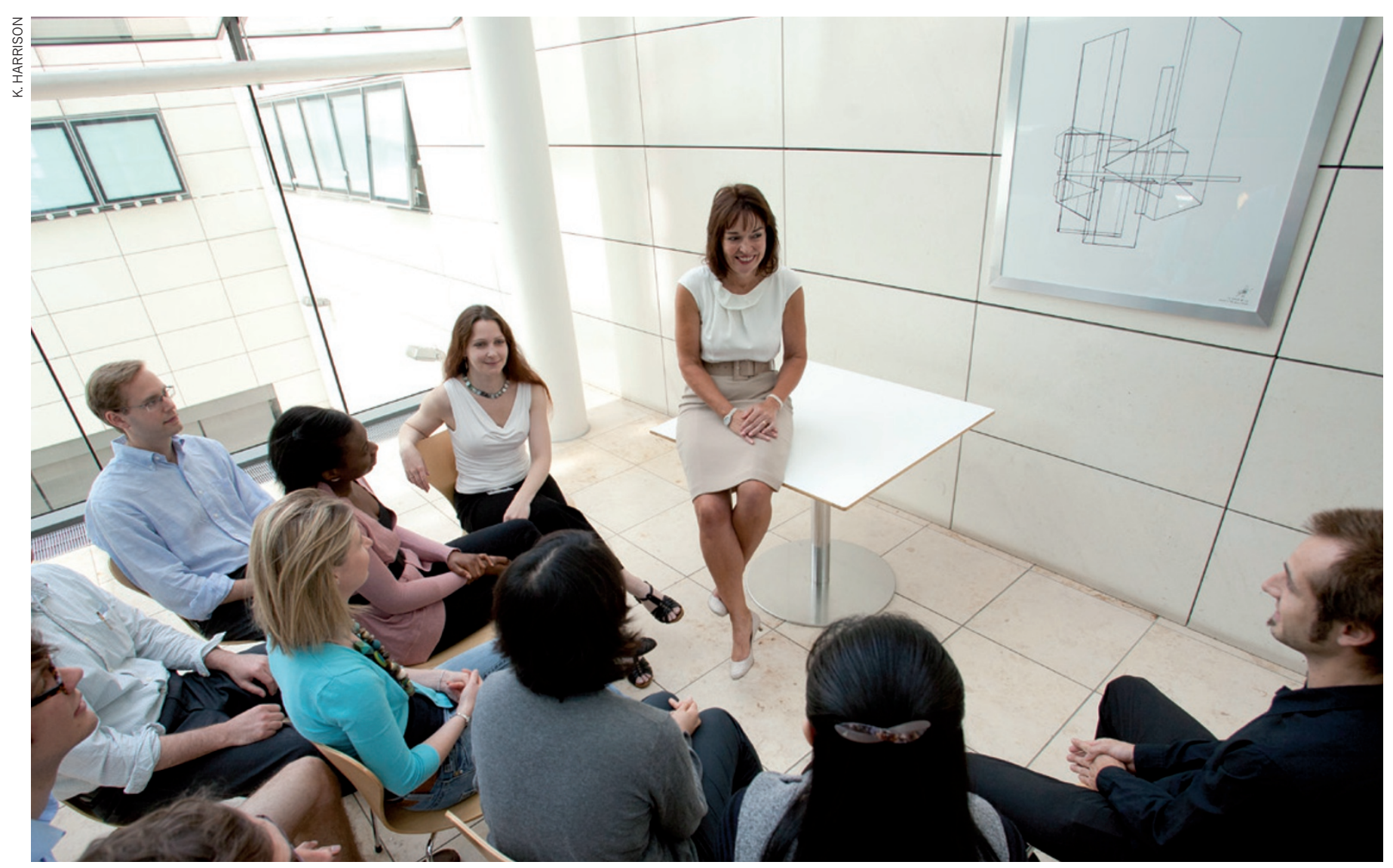

Women and chemistry do mix: Carol V. Robinson (centre) with members of her research lab at the University of Oxford, UK.

\title{
In pursuit of female chemists
}

\section{Chemistry needs new female role models and a less macho culture to appeal more to the next generation of young women, says Carol V. Robinson.}

A s the first female chemistry professor at both the University of Cambridge and the University of Oxford, which have a combined history in chemistry of about 800 years, I am often asked to comment on the poor retention of women chemists by UK universities. The decline from chemistry $\mathrm{PhDs}$ (46\% women) to professorships (just 6\%) is steeper than in other disciplines, including physics and engineering ${ }^{1}$. But numbers don't tell the whole story. Here I offer personal reflections from my career in chemistry about why women leave science.
The greatest attrition occurs during the transition from $\mathrm{PhD}$ to research. According to surveys done by the Royal Society of Chemistry in 2000 and 2008, this is when women become discouraged. They find laboratory research in chemistry too adversarial, the difficulties of combining career and family daunting and the lack of role models isolating ${ }^{2,3}$.

My role model and that of my generation of women chemists is Marie Curie, whose 1911 Nobel Prize in Chemistry we celebrate this year to mark the International Year of
Chemistry (she got her first Nobel, in physics, in 1903). Curie was often asked, especially by women, how she could combine family life with a scientific career. Her reply, "it has not been easy", resonates to this day. A century on from Curie's prize, as a mother of three, it is a question I, too, am often asked. One would hope for greater progress.

I was disappointed to read in a recent survey $^{4}$ that one-quarter of all 14-years-olds in the United Kingdom confuse Marie Curie with pop singer Mariah Carey. Perhaps we need new role models for today's women? 
> Curie's achievements might be too heroic and the sacrifices she made too great. If so, female chemists, including myself, can offer career narratives that defy the usual stereotypes and, hopefully, inspire others.

Unlike today's generation, I was inspired by Marie Curie's personal life story. Curie, a self-taught chemist, grew up in Warsaw; her father lost his job, forcing her to find work to help support her family. Similarly, my own full-time education ended at age 16 when my father lost his job. Consequently, I didn't follow the usual academic path, but after leaving school became a lab technician at Pfizer Corporation in Sandwich, UK.

Industry was a welcoming environment for me. I was passionately interested in mass spectrometry and began to keep notebooks of observations. My supervisors were impressed and encouraged me to attend night school. After seven years of part-time study and a year's full-time research for a master's degree, I qualified to study for a $\mathrm{PhD}$ at the University of Cambridge. At every stage, I felt I had to prove myself and worked hard. With limited PhD funding, I published five papers and wrote my thesis in less than two years.

Shortly after completing my $\mathrm{PhD}$ came the challenges of combining family life and career. I chose another unconventional route. I took an eight-year career break to cover the birth of my three children. I was warned that it was highly unlikely I would be able to return to science. I thought this was too high a price to pay for motherhood. Nowadays, when asked to talk to young women, I am often asked not to mention my career break, although I usually do. Sadly, it is not something that many institutions encourage.

\section{YOU CAN HAVE IT ALL}

Is the choice between children - and a normal family life - and becoming a professional scientist really so stark? I asked Ada Yonath, the only living female Nobel laureate in chemistry, how she balanced the demands of family and science. She replied that it is possible as long as you have a passion for both. I agree - we have to change the notion that academic jobs cannot be family friendly.
Admittedly, after my eight-year absence, it was hard to find a position in science. I had three interviews before convincing a panel that I was committed (one interviewer remembered me positively from my student days). It also wasn't easy being a postdoc when my children were school-age, but I was immensely productive in the morning. From about 5 a.m. my thoughts were clear. I had no interruptions and no guilt. As my children got older, I began to attend international meetings, often taking the children with me, even into the lecture hall. These sorts of opportunities to mix family and professional life are unparalleled in many other professions.

My research may also have benefited from having a career break. On returning in 1992, well-meaning academics tried to persuade

"Women me to follow fashionneed to adopt able pathways in promore 'male' years later, in metabocharacter lomics. But becoming traits to a principal investigator succeed." in my forties, much later than most, I was already several years behind the leading labs and not sufficiently excited by these trends. I needed to do something different.

"Nothing in life is to be feared, it is only to be understood," is my favourite quote from Curie, who, during her discovery of radioactivity, unknowingly exposed herself to great personal danger in her pursuit of the unknown. Fearlessness is one quality I have noticed among many successful chemists, men and women. Yonath did not take on easy projects and was regularly accused of being 'a dreamer'.

In my own lab, I pursued a path of putting macromolecular complexes into the gas phase of a mass spectrometer, not an obvious choice for the structural-biology questions I intended to ask. Well-respected scientists told me that the results would be meaningless. Happily, I chose not to follow too much of this advice. I might have been less brave had I been younger and more eager to please.

Chemistry has a reputation for being more cut-throat than biology or physics ${ }^{5}$. It has a macho culture in which getting to the finish line first is more important than how you get there. And women are assumed to be less competitive than men. There is some truth in this. Too often, female scientists shy away from responsible roles or don't have sufficient confidence or aspirations.

\section{CULTURE REINFORCEMENT}

Certainly, we can't blame men alone for creating a male-dominated environment when women scientists are often too keen to be invisible, or worse, to become honorary males, by adopting aggressive communication styles, say, or eschewing any interest in appearance. Curie herself proudly claimed that she had no dresses save the black one she wore every day to the laboratory. When I started at the University of Cambridge, I was advised not to dress so well by a female colleague, who warned I would be confused with the secretarial staff. Another colleague confessed to hiding shopping bags for fear of being considered too vain. But by behaving or dressing as honorary men, we only reinforce the macho culture of chemistry.

Consider how off-putting that might be to the younger generation. Let's start with our own daughters. "Would you advise them to go into science?" was a question recently posed to a small group of top American women scientists ${ }^{6}$. "Only if she is made of steel," was the consensus. I don't agree. I would have been very happy for my only daughter, a mathematician, to have been a chemist. I am proud of a mother-daughter publication resulting from her holiday research in my lab. Women don't need to adopt more 'male' character traits to succeed.

Today, 11 of the 20 people in my lab are women. I didn't set out to make it this way. I think women are drawn to the group, believing that I am likely to understand the conflicting demands of family and career. I am particularly proud of the many successful young women with families whom I have mentored, but I don't feel that I am doing anything special. I simply treat everyone as I would like to be treated myself - supported and nurtured. Perhaps all we can do is to change attitudes one research group at a time.
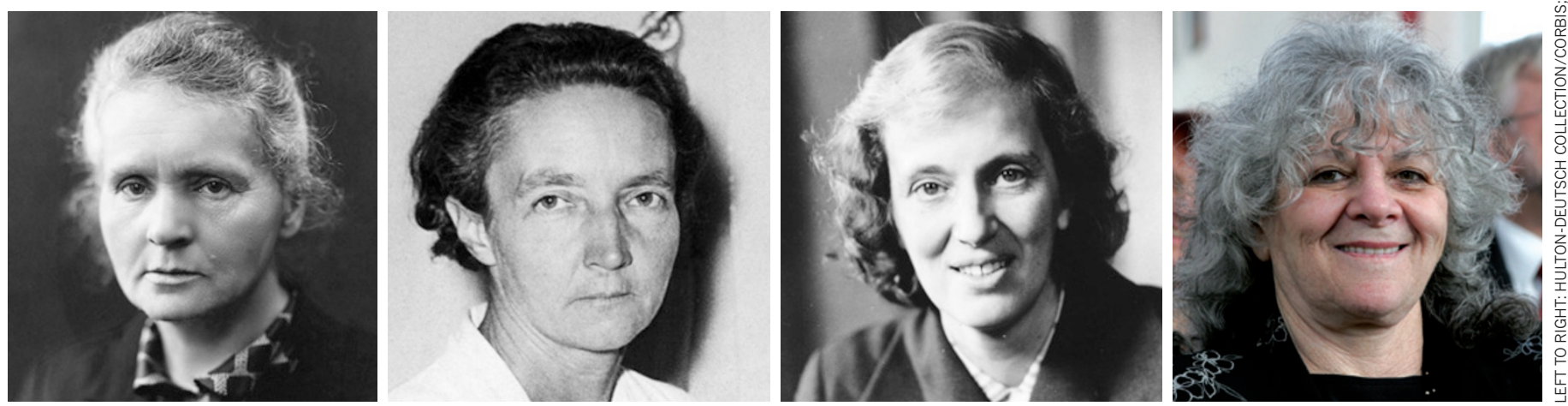

Four women have received the Nobel Prize in Chemistry: Marie Curie (1911), Irène Joliot-Curie (1935), Dorothy Hodgkin (1964) and Ada Yonath (2009). 
We must also challenge the patronizing cultural stereotypes that deter women. Headlines such as "Oxford housewife wins Nobel" and "One giant leap for womankind - and Israel" (for Nobel laureates Dorothy Hodgkin and Yonath, respectively) are par for the course. "Mother wins prize" and "Woman wins top science prize", are both newspaper headlines reporting my more modest achievements. The Rosalind Franklin award in 2004, from the Royal Society, came with a significant sum described as "a lot of money to spend on shoes". I confess to a weakness for shoes. But I in fact set up a fund to support visiting female lecturers and to establish a mentoring scheme for female postgraduates at Cambridge.

Attitudes to women in science have improved, but there is still some way to go. Yonath remembers a time when a visitor to her lab commented that her research was "so good that he thought it likely carried out by a man". As a junior researcher, I was asked many times "who is the senior man you work for?". Today, female postgraduates note less explicit biases that can make them feel excluded: from the all-male photos in chemistry departments, to the timing of early evening seminars, and the ensuing discussions in the local pub. So, we must all do more to support female chemists: by speaking out at injustice or prejudice, instead of staying quiet, and by encouraging talented colleagues to aspire to more demanding roles.

Curie encouraged her elder daughter to follow in her footsteps. Irène JoliotCurie received the second Nobel prize awarded to a woman in chemistry. As Marie Curie's granddaughter (herself a respected nuclear physicist) said: "We have to change the mentality that men are better scientists." Our daughters and granddaughters deserve nothing less.

Carol V. Robinson is a Royal Society research professor, Department of Chemistry, University of Oxford, South Parks Road, Oxford OX1 3QZ, UK. e-mail:carol.robinson@chem.ox.ac.uk

1. Royal Society of Chemistry Planning for Success: Good Practice in University Science Departments (RSC, 2008)

2. Royal Society of Chemistry Factors Affecting the Career Choices of Graduate Chemists (RSC, 2000)

3. Royal Society of Chemistry Change of Heart: Career Intentions and the Chemistry PhD (RSC, 2008).

4. Royal Institution 7 Questions on Scientists (BBC, 2011); available at go.nature.com/ rbj63x

5. Newsome, J. L. The Chemistry PhD: the Impact on Women's Retention (RSC, 2008).

6. Kolata, G. Women atop their fields dissect the scientific life (New York Times, 6 June 2011).

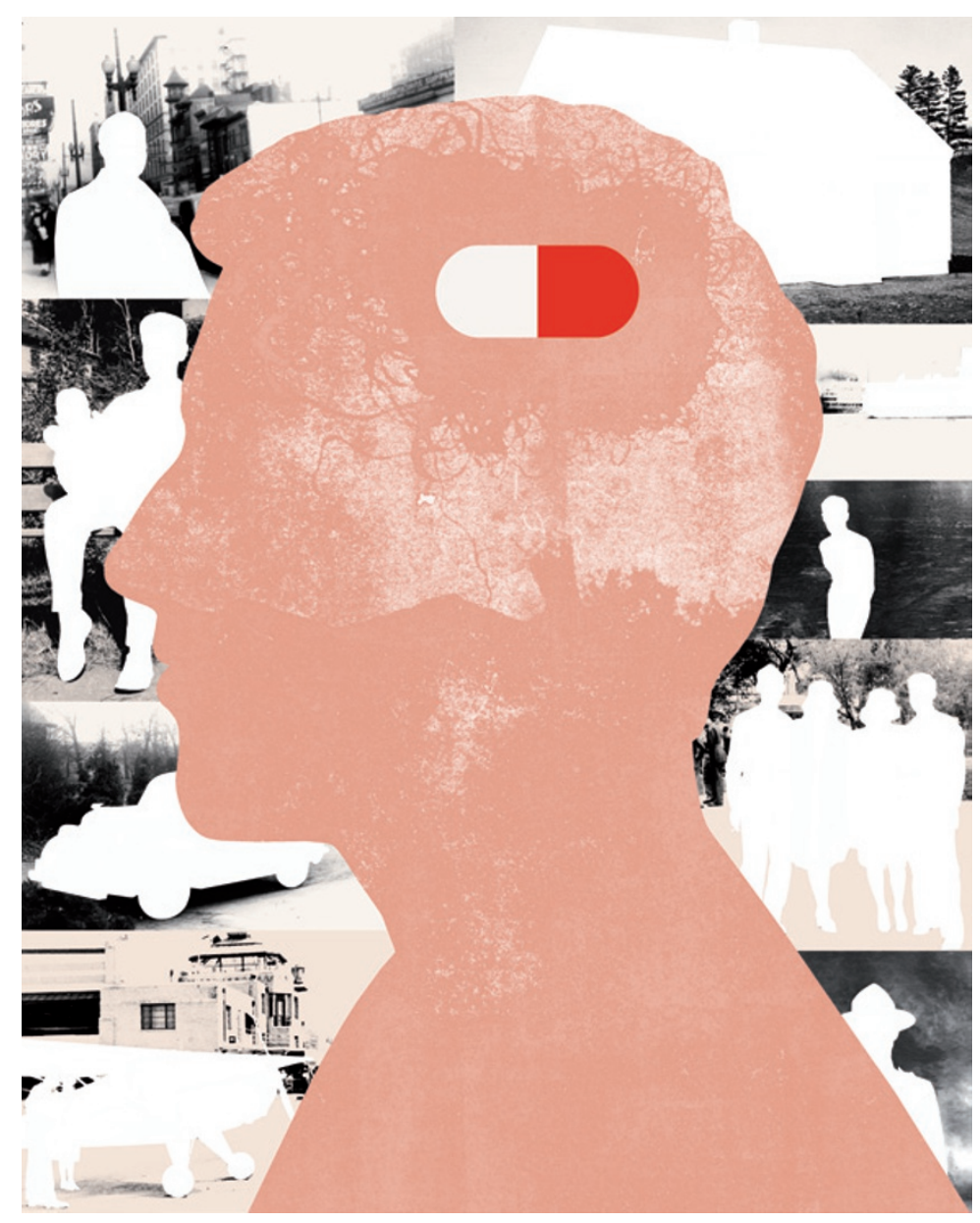

\title{
Give memory-altering drugs a chance
}

\author{
The ethical challenges of memory-dampening \\ drugs are likely to be manageable and the pay-offs \\ considerable, says Adam Kolber.
}

$\mathrm{S}$

everal studies suggest that memories can be pharmaceutically dampened. A few months ago, for instance, researchers showed that a drug called ZIP causes cocaine-addicted rats to forget the locations where they had regularly been receiving cocaine ${ }^{1}$. Other drugs, already tested in humans, may ease the emotional pain associated with memories of traumatic events. Indeed, the use of memory-altering drugs to treat addicts or victims of assaults, car accidents, natural disasters and terrorist attacks looks increasingly promising.

Many are alarmed by the prospect. As far back as 2003, the US President's Council on Bioethics issued a report that largely decried the use of such drugs ${ }^{2}$. Since then, journal articles and news stories have reiterated concerns that memory manipulators could interfere with the ability to lead true and honourable lives or could undermine a person's sense of identity.

The fears about pharmaceutical memory manipulation are overblown. Thoughtful regulation may some day be appropriate, but excessive hand-wringing now over the ethics of tampering with memory could stall research into preventing post-traumatic stress in millions of people. Delay could also hinder people who are already debilitated by harrowing memories from being offered the best hope yet of reclaiming their lives.

Various drugs are being investigated ${ }^{3,4}$. Propranolol, for instance - which is 